\title{
Acceptance and Compliance issues of nasal CPAP amongst Indian patients of obstructive sleep apnea
}

\author{
J.C.Suri, M.K.Sen, U.C.Ojha
}

ABSTRACT

Three hundred patients of obstructive sleep apnea were selected for this study. Subjective (questionnaire-based) and objective (usage-profile report based) assessments of usage of nasal CPAP in this population were carried out. Several factors responsible for non acceptance and poor compliance were identified, which included causes related to social, economic, cultural and geographical parameters peculiar to our country. In conclusion, some remedial measures are suggested.

Keywords: nasal continuous positive airway pressure therapy, compliance, obstructive sleep apnea, adherence, acceptance

Indian J Sleep Med 2006; 1.4, 197-203

\section{Introduction}

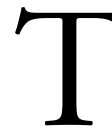
$\mathbf{T}$ reatment of OSA syndrome is acceptably optimized only with nasal continuous airway pressure (nCPAP) therapy. It involves the nightly, volitional use of a mechanical device. This form of therapy, as opposed to "taking a medication", understandably poses an obstacle on the part of the patient. The first such obstacle or resistance offered by the patient is the "acceptance" of nCPAP, defined as the patient's willingness to be set up in the home after the titration night (1) "Compliance" with nCPAP is defined as the adherence to treatment with nCPAP once the patient has agreed to initiate therapy. Attempts to determine compliance to nCPAP, as assessed by subjective methods, yielded compliance rates from 65\% to $90 \%{ }^{(2-7)}$. It was mainly the patient's perception of improvement and not the severity of obstructive sleep

Address for correspondence:

Dr. J. C. Suri

Senior Chest Physician \& Head

Department of Pulmonary,

Critical Care \& Sleep Medicine,

Vardhman Mahavir Medical College \&

Safdarjang Hospital, New Delhi

jcsurijc@del3.vsnl.net.in

jcsuri@rediffmail.com disordered breathing that seemed to predict acceptance and compliance of patients ${ }^{(8,9)}$. Objective assessment of compliance, as assessed by incorporating an hourmeter into the nCPAP unit, however yielded significantly lower values ${ }^{(10)}$. Models comprising psychological as well as clinical variables have more recently been used as predictors of adherence to nCPAP. ${ }^{(11,12)}$ The software present in newer generation $\mathrm{nCPAP}$ devices that allows monitoring more precise patterns of use (time at pressure on individual nights) are capable of revealing more information on compliance issues. The minimal duration of nCPAP use that may be regarded as "acceptable" to decrease daytime sleepiness can also be thus determined.. It has also been shown that patients using a auto-titrating, self-adjusting device (APAP) wear it longer during nights they use the pressure support system and were more prone to continue treatment ${ }^{(13)}$. Attending patient nCPAP education and support groups has also been shown to improve compliance in older men with obstructive sleep apnea (OSA). ${ }^{(14)}$

Sleep medicine is a relatively nascent discipline in developing countries like India. Several factors (including socio-economic, ethnic, cultural and geographic) may influence nCPAP compliance in our country. This study was aimed at objectively analyzing data pertaining to nCPAP compliance in Indian patients. Majority of studies that have looked into compliance issues with

Indian Journal of Sleep Medicine (IJSM), Vol. 1, No. 4, 2006 
CPAP have mainly concentrated on technical reasons for non-adherence and not included socio-cultural issues into their consideration. Such issues have been covered in the present study.

\section{Material \& Method}

Twelve hundred patients of Obstructive Sleep Apnea attending the sleep clinic of the Department of Pulmonary, Critical Care \& Sleep Medicine, V.M. Medical College \& Safdarjang Hospital, New Delhi during the preceding 5 years, were included in this study. It was primarily aimed at determining the acceptance and compliance to nasal CPAP device prescribed to these patients and identifying possible causes of non-acceptance and poor compliance in appropriate cases. They were all diagnosed as obstructive sleep apnea syndrome on the basis of a full night, supervised, manually validated level- I polysomnography done in the sleep laboratory of the hospital.

A detailed history and physical examination was performed in all patients. They were required to fill a sleep questionnaire outlining important epidemiological and sleep history and daytime sleepiness. This was followed by a diagnostic polysomnography and nCPAP titration using an Alice 3 Healthdyne polysomnography system. Each patient was monitored with standard polysomnography with two channels each for EEG and EOG, one each for submental EMG, airflow (thermistor), chest and abdominal wall motion (strain gauges), arterial oxygen saturation (pulse oximetry), ECG, snore, body position and CPAP pressure (monitored by CPAP remote control and manometer). nCPAP was always

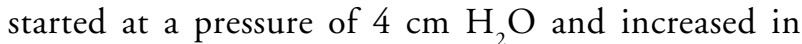
increments of $1 \mathrm{~cm} \mathrm{H} \mathrm{H}_{2} \mathrm{O}$ to abolish all respiratory events (apneas, hypopneas, flow limitations, and arousals) and snoring. At least 20 minutes were spent at each nCPAP pressure to fully evaluate its effectiveness.

All patients underwent a full nCPAP education session with the physician that included explanation of CPAP, selection of a nCPAP mask, determination of mask size and a several-minute trial of CPAP before polysomnography. An appropriate nCPAP system was then prescribed.

Every patient was followed up by the physician over the next 6 to 8 weeks including the facility for telephonic contact. The standard routine was to review the patient 7 days after the nCPAP set-up, every month during the next 3 months after the set-up, and subsequently every 3 months. In case of any problems (mask discomfort, rhinorrhea etc) these were approached according to standard guidelines. Mask leaks were addressed initially by adjusting the head-gear, and if this failed, the mask was changed. For nasal dryness, nasal saline was tried initially, and a humidifier was added if it persisted. Patients with chronic nasal congestion were treated with steroid nasal spray at least two weeks before starting CPAP titration.

Each patient was also required to fill up a questionnaire regarding use of nasal nCPAP at every follow up. The sleep questionnaire included questions regarding number of hours used per night, number of times and duration of removal of mask, reasons for removal, nasal symptoms if any, mask related problems and reasons for not using. He was also required to fill the Epworth Sleepiness Scale at every follow up visit. The number of hours of actual pressuring of nCPAP device was also assessed by downloading and interpreting the follow-up data that was objectively determined by the software incorporated in the device.

\section{Results}

Of the twelve hundred patients only three hundred (25\%) ultimately accepted nasal CPAP therapy. The reasons for non acceptance are outlined in Table 1. They included high cost of CPAP machine, finding it obtrusive, social stigma, the idea of using a device life long not acceptable and looking for alternative therapies. Fifty percent of the patients observed the protocol of follow-up. About $25 \%$ eventually discontinued treatment; $70 \%$ of them used it for more than 4 hrs per night for more than $70 \%$ of days in a month. Patients were found to over-report compliance subjectively when compared to objective measurement with the hour meter. The most crucial part of follow-up was found to be during the early period or first month when problems pertaining to adaptation, teething and troubleshooting were required. Patients with a severe degree of disease were found to be most compliant. In the later part, after 6 months, when patients improved they were found to become irregular and require reinforcement. Factors influencing the usage included initial severity of disease, patient education and follow-up, patient's intrinsic behavior and use of humidifier. The mask related problems were pressure sores in $10 \%$, persistent air leaks in $25 \%$, claustrophobia (17\%), nasal bleed (8\%), strap related problems $(25 \%)$ 
and tube related problems (17\%). Factors interfering with regular use included power failure $(50 \%)$, frequent traveling ( $12 \%)$, problems relating to kids ( $10 \%$ ), seasonal rhinitis/ asthma (5\%), financial (expensive repair) $(10 \%)$, hostile weather conditions (15\%) (Table 2 ). Reasons for removing nCPAP during night were found to be urinary complaints in $42 \%$, inadvertent removal in $11.6 \%$, sleep disturbance in $16.6 \%$ and anxiety /depression in $20 \%$ patients. The number of removals per night was found to be once in $37.8 \%$, twice in $21 \%$ and more than twice in $8.3 \%$ cases (Table 3 ) . The nasal problems reported are depicted in Figure-1 and those pertaining to the mask in Figure-2.

Table 1: Reasons for not initiating treatment

\begin{tabular}{|l|c|}
\hline \multicolumn{1}{|c|}{ Reason } & Percentage of contribution \\
\hline Cost & $85 \%$ \\
\hline Finding it obtrusive & $20 \%$ \\
\hline Social Stigma & $30 \%$ \\
\hline $\begin{array}{l}\text { Idea of using a device life long } \\
\text { not acceptable }\end{array}$ & $40 \%$ \\
\hline Looking for alternative therapy & $35 \%$ \\
\hline
\end{tabular}

Table 2:Factors interfering with regular use of nCPAP

\begin{tabular}{|l|c|}
\hline Factor interfering with use & Percentage \\
\hline Power failure & $50 \%$ \\
\hline Frequent Traveling & $12 \%$ \\
\hline Problems relating to kids & $10 \%$ \\
\hline Seasonal rhinitis/Asthma & $5 \%$ \\
\hline Financial (Expensive repair) & $20 \%$ \\
\hline Hostile weather conditions & $15 \%$ \\
\hline
\end{tabular}

Table 3: Reasons for removing CPAP during night

\begin{tabular}{|l|c|}
\hline Item & Percentage of contribution \\
\hline Once & 37.8 \\
\hline twice & 21 \\
\hline More than twice & 8.3 \\
\hline Urinary complaints & 42 \\
\hline Inadvertent removal & 11.6 \\
\hline Sleep disturbance & 16.6 \\
\hline Anxiety / depression & 20 \\
\hline
\end{tabular}

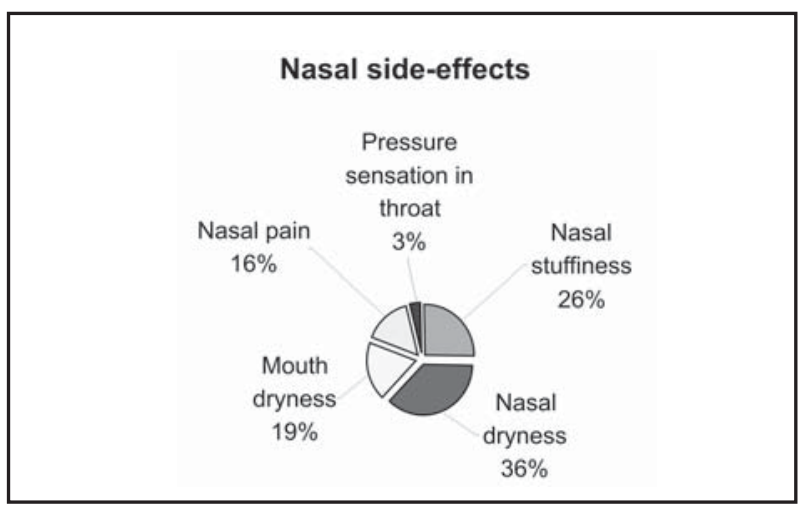

Fig 1: Nasal side effects

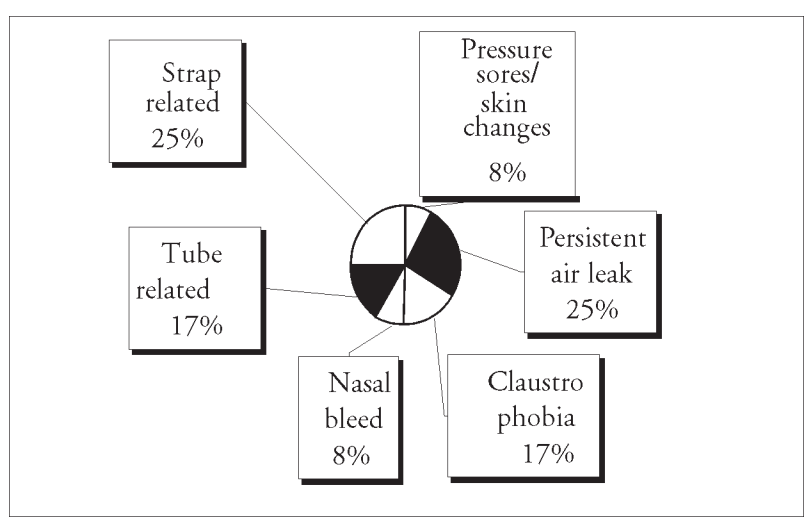

Fig 2: Mask-related problems

\section{Discussion}

This study by and large revealed that in the patient population included herein, $75 \%$ patients never initiated the therapy; among acceptors $30 \%$ eventually discontinued treatment and $70 \%$ of those who continued with the device used it for more than 4 hours per night for more than $70 \%$ of the days in a month. The rates of initial refusal of CPAP (before or within the week after titration) varies from 5 to $50 \%$ of patients in whom CPAP is recommended or titrated ${ }^{(4,15-22)}$. The rate of initial refusal in the present study was found to be $75 \%$. This is significantly larger than that in any of the abovementioned studies. The reasons for not initiating treatment included cost, finding the device obtrusive, social stigma, the idea of using a device life long not being acceptable and looking for alternative therapies in indigenous and contemporary systems of medicine (like homeopathy, acupressure, yoga, acupuncture and Indian Journal of Sleep Medicine (IJSM), Vol. 1, No. 4, 2006 
naturopathy). Unlike in the US where medical insurance companies finance CPAP devices, or in the UK where the state funds it, in India only a small percentage of patients (like Central Government employees, industrial workers who are ESI beneficiaries and other third party beneficiaries) have access to funding agencies. A large majority of patients have to bear all the expenses by themselves and quite frequently find it beyond their means to do so. Approximately $20 \%$ of our patients had apprehensions that the huge initial expenditure might as well end up being wasteful in case the device eventually did not suit them. In some such patients, arrangements were made to initially provide them with the device on a rent-free trial for a limited period till their apprehensions were thus allayed. Initial acceptance was found to improve in these patients. About twenty percent our patients found it obtrusive to wear a mask and get hooked to a machine overnight. Approximately thirty percent cases attached a social stigma to the use of a machine. Majority of the patient population lived in small houses and did not have the privacy of an exclusive bedroom which they had to share with their children. In the very social and cultural fabric of our country, the personal use of any machine (such as CPAP) is often a stigma. Surgical techniques for correction of OSA are not well developed in our country, or for that matter anywhere in the world. Hence CPAP is the only viable treatment for this condition till date. The use of such a machine life long is often not acceptable to a large segment of patients that therefore turns to the wide array of alternative medicine existent in the country.

The rates of discontinuation of CPAP among patients who initially accept it has varied between $12 \%$ and 25\% in various studies ${ }^{(4,15-21,23-33)}$. An initial steep fall-off is often followed by leveling of rates after 3 to 4 years. In the present study, as mentioned earlier, $30 \%$ of patients were eventually found to have discontinued treatment. The rates were again higher than those in the aforementioned studies Irregular use and discontinuation was also found to be quite high amongst patients of this study. Power failure was the major cause for irregular use found in about $50 \%$ cases. Long hours of power failure are a frequent problem in major cities and towns. One solution that was used in our patients was asking them to use uninterrupted power supply (UPS) systems and this resulted in significant improvement in adherence, albeit at the cost of higher expenses. Secondly due to frequent fluctuation of voltage particularly in summer months leading to damage to the power supply unit of the machine. In addition the excessive heat, humidity $\&$ dust lead to over heating of the machine resulting into sudden stopping of the equipment. The ensuing damage makes them less durable and their repairs become more expensive. About $20 \%$ of our patients had to discontinue use of CPAP due to financial constraints pertaining to expensive repair and maintenance of the equipment. Weather conditions in India are hostile. Most houses are not air-conditioned, thus patients tend to discontinue the use of their machines in extremes of summer and winter months. Moreover, children, who often sleep with their parents, during their illness, compel their parents to discontinue the use of their own CPAP devices in the interest of childcare.

Intermittent asthma/rhinitis, anxiety and depression are common co-morbidities with OSAS. Anxiety and depression are independently associated with disorders of initiation and maintenance of sleep. Anxiety is associated with sleep onset insomnia. Such anxious patients who are thus still not asleep often find it difficult to tolerate the necessary CPAP pressures, once the conventional ramp period is over. Depression is frequently associated with midnight awakenings with inability to get back to sleep easily; during such periods CPAP pressure is again poorly tolerated. Patients of congestive heart failure $(\mathrm{CHF})$ and OSA, when treated with CPAP, often develop central events (complex sleep apneas) and thus tolerate CPAP poorly. In this study, $20 \%$ such patients with co morbid conditions were identified and appropriately treated. This practice resulted in improvement in compliance. It is suggested that patients of OSAS with co morbid allergic rhinitis/ asthma, anxiety, depression and CHF comprise a high risk group for poor CPAP compliance and hence the need to screen all patients of OSA for co-morbidity. These high-risk patients also require more frequent and close follow-up.(Table 4)

Table 4: Risk factors for poor compliance

* Presence of co-morbidity
- Anxiety Neurosis
- Depression
- Asthma,
- COPD
- Allergic Rhinitis
- Congestive heart failure
* Personality traits (phobic)
*hose requiring high pressures


"Non-compliance" of CPAP use, defined as use on $<70 \%$ nights and by $<4$ hours on these nights, occurs in $21-46 \%$ of patients by three months in most case series $(25,27,34)$. In this study the figure was found to be comparable at $30 \%$. Sub-optimal use of CPAP may be analogous to non-adherence to pharmacotherapy that is seen in any chronic ailment like chronic bronchial asthma or essential hypertension.

Most studies that have looked into compliance issues of CPAP therapy have noticed side-effects of the device that was experienced by most patients (almost two-third) to a greater or lesser degree ${ }^{(2,3,20,21,27,32,33,35,36)}$. The various side-effects pertaining to nasal and mask-related issues in this study are depicted in Figures 1 and 2. The nasal and mask related side effects were also higher in our group of patients. Strap related causes (25\%) were ascribed to the high atmospheric heat and humidity in our part of the country. Poor mask fitting often led to air leakage which invariably leads to increased flow leading on to nose and mouth dryness. The high rate of nasal symptoms had seasonal variations, being more severe in the months of March-April and DecemberJanuary in patients hailing from the northern parts of the country. Some facts that may be peculiar to Indian patients need to be highlighted. Firstly, the masks used with nCPAP units that are procured from the western countries need not necessarily always conform to the cranio-facial features of Indian subjects. Hence sideeffects like mask-misfits and nasal bridge excoriations are frequently encountered. Secondly, humidification is a major problem in several Indian regions which face extremes of climatic conditions that are dry and warm; hence humidifiers are quite frequently to be procured as "add-on" supplements with CPAP units. Mouth dryness (19\%), nasal dryness (36\%) and nasal stuffiness (26\%), the latter being found to be more in cases requiring nCPAP pressure of $>12 \mathrm{~cm} \mathrm{H} 2 \mathrm{O}$, were significantly improved in our group of patients with the use of a humidifier. Traditionally, many methods have been tried to decrease side effects. They range from use of heated humidifier, custom-made straps, use of topical nasal saline drops or steroid spray (allergic rhinitis), a change from nasal to full-face mask or use of nasal pillows. Social factors observed in patients belonging to joint families where co-habitation with siblings and other relatives, sleeping with children in the same room are frequently practiced, were often found to pose a problem to the use of any device regularly during sleep. It may be mentioned that all these features that were observed in this study may be unique to countries like India

It has also been found that, unlike in the developed world, due to a lack of a support system to contact the patient or send reminder call, the frequency of follow up depended upon the response to treatment.

Medical literature is replete with well-designed trials to ascertain compliance with the device amongst CPAP users ${ }^{(37)}$. A pressure monitor and real time clock incorporated in the device allows reporting on compliance in terms of regularity and length of sleep on nCPAP that show modest correlations with baseline polysomnographic features ${ }^{(38)}$. Attempts to study the relationship between such objectively measured nCPAP compliance and variables from social cognitive theory and the transtheoretical model have revealed that measurement of such modifiable factors can provide the basis for sound interventions to improve nCPAP compliance ${ }^{(39)}$. Amongst those of our patients in whom CPAP machines which had the capability to store compliance data that could later be downloaded were used, they were found to be helpful in analyzing specific problems in this patient population. This method was found to give an insight into the patient's reasons for not using the device.

The findings of this study have added to the traditional wisdom about nCPAP compliance as outlined in similar work from the western hemisphere. Based on the problems unique to this part of the world, pertaining to social, economic, cultural and geographical factors, certain directions for the future are being suggested.

a) Reducing the financial burden on the patient (local manufacturing of machine \& accessories, easy financial schemes, rationalization of pricing, monthly rental scheme)

b) Modifications in machine and accessories (suitable to Indian scenario, mask/strap according to local facial features)

c) Education (regarding the morbidity \& mortality of untreated or poorly treated OSA, improve awareness among doctors and general public

d) Use of alternative methods (Oro dental devices improved surgical techniques)

e) Organizing nCPAP Users' Clubs (to gain confidence and share their experiences for better compliance).

Indian Journal of Sleep Medicine (IJSM), Vol. 1, No. 4, 2006 


\section{Conclusions}

Compliance issues in patients of obstructive sleep apnea, like any other chronic disease, have bogged the physician since inception of the therapeutic measures designed for this clinical entity. Attempts to determine some of the factors responsible for non -acceptance and poor compliance to nasal CPAP in such patients in India were made. Suggestions to improve compliance have been outlined.

\section{References}

1. Strollo PJ, Sanders $\mathrm{MH}$, Atwood $\mathrm{CH}$. Positive pressure therapy. Clin Chest Med 1998; 19:55-68.

2. Hoffstein V, Viner S, Mateika S, et al. Treatment of obstructive sleep apnea with nasal continuous positive airway pressure patient compliance, perception of benefits, and side effects. Am Rev Respir Dis 1992; 145:841-845.

3. Nino-Murcia G, McCann CC, Bliwise DL et al. Compliance and side effects in sleep apnea patients treated with nasal continuous positive airway pressure. West J Med 1989; 150:165-169.

4. Rauscher H, Popp W, Wanke T, et al. Acceptance of CPAP therapy for sleep apnea. Chest 1991; 100:1019-1023.

5. Rolfe I, Olson LLG, Saunders NA. Long term acceptance of continuous positive airway pressure in obstructive sleep apnea. Am Rev Respir Dis 1991; 114:1130-1133.

6. Sanders MH, Gruend L CA, Rogers R M. Patient compliance with nasal CPAP therapy for sleep apnea. Chest 1986; 90:330-333.

7. Waldhorn RE, Harrick TW, Nguyen MD, et al. Long-term compliance with nasal continuous positive airway pressure therapy of obstructive sleep apnea. Chest 1990; 97:3338 .

8. Engleman H. Self-reported use of CPAP and benefits of CPAP therapy. Chest 1996; 109:1478-1476.

9. Engleman HM, Martin SE, Douglas NJ. Compliance with CPAP therapy in patients with sleep apnea/hypopnea syndrome. Thorax 1994; 49:263-266.

10. Kribbs NB, Pack Al, Kline AR et al. Objective measurement of patterns of nasal CPAP use by patients with obstructive sleep apnea. Am Rev Respir Dis 1993; 147:887-895.

11. Wild MR, Engleman HM, Douglas NJ, Espie CA. Eur Respir J 2004; 24(3):461-465.

12. Drake CL, Day R, Hudgel D, Stefadu Y, Parks M, Syron ML, Roth T. Sleep during titration predicts continuous positive airway pressure compliance. Sleep 2003; 26:308-311.

13. Hudgel DW, Fung C, A long term randomized, cross-over comparison of auto-titrating and standard nasal continuous airway pressure. Sleep 2000; 23(5):645-648.

14. Mc Ardle N, Devereux G, Heidarnejad H, et al. Long-term use of CPAP therapy for sleep apnea/hypopnea syndrome.

\author{
Am J Respir Crit Care Med 1999; 159:1108-1114.
}

15. Kreiger J. Long-term compliance with CPAP therapy in obstructive sleep apnea patients and in snorers. Sleep 1996; 19:S136-S143.

16. Kreiger J. Long-term compliance with nasal continuous positive airway pressure (CPAP) in obstructive sleep apnea patients and non-apneic snorers. Sleep 1992;15:S42-S46.

17. Lacussagne $\mathbf{L}$, Didier A, Doussan S, et al. Results of 248 patients with sleep apnea syndrome treated by continuous positive airway pressure ventilation between 1990 and 1995: a study of compliance and outcome of apneahypopnea index. Revue des Maladies Respiratoires 2000; 17:467-474.

18. Pieters T, Collard P, Aubert G, et al. Acceptance and longterm compliance with nCPAP in patients with obstructive sleep apnea syndrome. Eur Respir J 1996; 9:939-944.

19. Waldhorn RE, Herrick TW, Nguyen MC, et al. Long term compliance with nasal continuous positive airway pressure therapy of obstructive sleep apnea. Chest 1990; 97:3338.

20. Meurice J-C, Dore P, Paquereau J, et al. Predictive factors of long term compliance with nasal continuous positive airway pressure treatment in sleep apnea syndrome. Chest 1994; 105:429-433.

21. Fleury B, Rakatonanahary D, Tehindrazanarivelo A D, et al. Long term compliance to continuous positive airway pressure therapy (nCPAP) set up during a split-night polysomnography. Sleep 1994; 17:512-515.

22. Edinger J D, Carwile S, Miller P, et al. Psychological status, syndromatic measures, and compliance with nasal CPAP therapy for sleep apnea. Perceptual and Motor Skills 1994; 78:1116-1118.

23. Kingshott $\mathbf{R}$ N, Vennelle $M$, Hoy $C J$ et al. Predictors of improvements in daytime function outcomes with CPAP therapy. Am J Respir Crit Care Med 2000; 161:866-871.

24. Pepin J L, Krieger J, Rodenstein D, et al. Effective compliance during the first 3 months of continuous positive airway pressure; a European prospective study of 121 patients. Am J Respir Crit Care Med 1999; 160:1124-1129.

25. Reeves-Hoche $\mathbf{M}$ K, Meck R, Zwillich CW, et al. Nasal CPAP: an objective evaluation of patient compliance. Am J Respir Crit Care Med 1994; 149:149-154.

26. Kribbs N B, Pack Al, Kline LR, et al. Objective measurement of patterns of nasal CPAP use by patients with obstructive sleep apnea. Am Rev Respir Dis 1993; 147:887-895.

27. Weaver T E, Kribbs NB, Pack Al, et al. Night-to-night variability in CPAP use over the first three months of treatment. Sleep 1997; 20:278-283.

28. Bennett L S, Langford BA, Stradling JR, et al. Sleep fragmentation indices as predictors of daytime sleepiness on nCPAP response in obstructive sleep apnea. Am J Respir Crit Care Med 1998; 158:778-786.

29. Meslier N, LeBrun T, Griller-Lanoir, et al. A French survey of 3225 patients treated with CPAP for obstructive sleep apnea: benefits, tolerance, compliance and quality of life. Eur Respir J 1998; 12:185-192. 
30. Janson C, Noges E, Svedberg-Randt S, et al. What characterizes patients who are unable to tolerate continuous positive airway pressure (CPAP) treatment? Respir Med 2000; 94:145-149.

31. Engleman $\mathbf{H} \mathbf{M}$, Asgari-Jirhandeh $N, M c L e o d ~ A L$, et al. Self-reported use of CPAP and benefits of CPAP therapy. Chest 1996; 109:1470-1476.

32. Rauscher H, Formanek D, Popp W, et al. Self-reported vs measured compliance with nasal CPAP for obstructive sleep apnea. Chest 1993; 103:1675-1680.

33. Engleman H $\mathbf{M}$, Wild MR. Improving CPAP use of patients with sleep apnea/hypopnea syndrome (SAHS). Sleep Medicine Reviews 2003; 7(1):81-99.

34. Pepin J L, Leger $P$, Veale D, et al. Side effects of nasal continuous positive airway pressure in sleep apnea syndrome. Chest 1995; 107:375-381.
35. Kalan A, Kenyon GS, Seemungal TA, et al. Adverse effects of nasal continuous positive airway pressure therapy in sleepapnea syndrome. J Laryngol Otol 1999; 113:888-892.

36. Russo-Magno P, O'Brien A, Panciera T, Rounds S. Compliance with CPAP therapy in older men with obstructive sleep apnea. J Am Geriatr Soc 2001 49:1205-1211.

37. White DP, Gibb TJ. Evaluation of Healthdyne Nightwatch System to titrate CPAP in the home. Sleep 1997; $21: 198-$ 204.

38. Noseda A, Jann E, Hoffmann G, et al. Compliance with nasal continuous positive airway pressure assessed with a pressure monitor: pattern of use and influence of sleep habits. Respir Med 2000; 94:76-81.

39. Stepnowsky CJ, Marler MR, Ancoli-Israel S. Determinants of nasal CPAP compliance. Sleep Med 2002; 3(3); 239247. 